\title{
The Early Presentation of Dementia in People with Down Syndrome: a Systematic Review of Longitudinal Studies
}

\author{
Bianca Alexandra Lautarescu ${ }^{1}$ (D) - Anthony John Holland ${ }^{1} \cdot$ Shahid H. Zaman ${ }^{1}$
}

Received: 8 April 2016 / Accepted: 27 January 2017 /Published online: 13 March 2017

(C) The Author(s) 2017. This article is published with open access at Springerlink.com

\begin{abstract}
Adults with Down syndrome (DS) are at a very high risk of developing early onset Alzheimer's disease (AD) due to trisomy of chromosome 21 . AD is preceded by a prolonged prodromal "pre-clinical" phase presenting with clinical features that do not fulfil the diagnostic criteria for AD. It is important to clinically characterise this prodromal stage to help early detection of the disease as neuropathology of $\mathrm{AD}$ is almost universal by the fifth decade in DS. There is a lack of knowledge of the trajectory of decline associated with the onset of dementia in this population and early signs may be overlooked or misdiagnosed, negatively affecting the quality of life of those affected and the use of early pharmacological or psychosocial interventions. The objective of this systematic review is to evaluate the published literature on longitudinal data in order to identify the cognitive and behavioural changes occurring during the prodromal and early stages of $\mathrm{AD}$ in this population. Fifteen peer-reviewed articles met the inclusion criteria, including a total number of 831 participants, with the duration between baseline and follow up varying from 1 year to 47 years. Results suggest that, compared to the general population for which short-term (episodic) memory loss is the most common indicator associated with the onset of $\mathrm{AD}$, in people with $\mathrm{DS}$, executive dysfunction and Behavioural and Psychological Symptoms of Dementia (BPSD) are commonly observed during pre-clinical and early stages and may precede memory loss. The review highlights the importance of using a broad spectrum of assessments in
\end{abstract}

Bianca Alexandra Lautarescu

a.lautarescu@cantab.net

1 Cambridge Intellectual and Developmental Disabilities Research Group, Department of Psychiatry, University of Cambridge, Douglas House, Trumpington Road, Cambridge CB2 8AH, UK the context of heterogeneity of symptoms. Theoretical and practical implications are discussed, as well as the need for further research.

Keywords Down syndrome · Alzheimer's disease · Dementia $\cdot$ Ageing $\cdot$ Systematic review $\cdot$ Longitudinal

\section{Background}

Alzheimer's disease (AD) is a neurodegenerative disorder characterized histopathologically by neuronal death, neuritic plaques and neurofibrillary tangles and clinically by a progressive and irreversible deterioration in cognition and behaviour (McKhann et al. 2011). The greatest prevalence of early onset $\mathrm{AD}$ is found in individuals with Down Syndrome (DS), with symptoms appearing before the age of 65 (Hartley et al. 2014) and approximately three-quarters of people with DS over 60 showing clinical evidence of dementia (Lai and Williams 1989). As the life expectancy of people with DS has increased from an estimated mean of 12 years in 1940, to over 60 years now (Bittles and Glasson 2004), the focus of research and of clinical services now includes adulthood and later life.

The later stages of $\mathrm{AD}$ in people with $\mathrm{DS}$ have been documented and are reportedly similar to symptoms exhibited by people with $\mathrm{AD}$ in the general population (Strydom et al. 2010). However, limited information is available with regards to cognitive and behavioural changes prior to diagnosis or during the very early stages (Adams and Oliver 2010). While in the general population the prodromic stage of $\mathrm{AD}$ is characterized by impairments in episodic memory, a number of qualitative studies involving people with DS have suggested that the progression of AD in people with DS (DSAD) might be more similar to dementia of the frontal type in the typically developing population, with Behavioural and 
Psychological Symptoms of Dementia (BPSD) and impairment of executive functions (i.e. goal directed behaviours such as planning, attention, judgement etc.) preceding memory impairments (Deb et al. 2007).

Previous research has also indicated that carers often lack basic knowledge regarding the risk for dementia in this population and are not aware of the symptoms that they should be vigilant for in ageing individuals (Bittles and Glasson 2004). The present paper aims to address this gap in the literature and we report findings from a systematic review of the trajectory of changes that accompany the onset of dementia in this population (i.e. before the formal diagnostic criteria of $\mathrm{AD}$ are fulfilled). If there is evidence for an atypical presentation of dementia, such as BPSD and executive dysfunction preceding the development of sufficient symptoms to meet the diagnostic criteria of dementia, this might partially account for the discrepancy between the almost universal presence of neuropathology from age 40 years onwards and the lower (than expected) prevalence rates for clinically diagnosed dementia (Ball et al. 2006) given the prevalence rate of neuropathology. Identifying symptoms that characterize pre-clinical and early $\mathrm{AD}$ in people with $\mathrm{DS}$ is necessary before further research and clinical interventions, which link findings from neuropathology, putative biomarkers or neuroimaging (Annus et al. 2015) with cognitive features, can be undertaken. Lastly, as new pharmaceutical therapies are developed it is necessary to have reliable measures of performance in all relevant outcome domains so that effectiveness of treatments can be evaluated.

\section{Methods}

A systematic review was undertaken following the guidelines provided by PRISMA (i.e. Preferred Reporting Items for Systematic Reviews and Meta-Analyses: http://www.prismastatement.org/) and the Cochrane Collaboration (http://www. cochrane.org/). Potentially relevant studies were identified through searches in citation indexing databases: PubMed (Medline) and PsycInfo, as it has been suggested that they provide broad coverage of biomedical publications worldwide (SuarezAlmazor et al. 2000). Within the electronic database, the search was limited to peer-reviewed journals published between 2000 and 21.01.2015 and included the following terms (("Down syndrome"[Title/Abstract] OR "Down"s syndrome"[Title/Abstract])) AND ("Alzheimer"[Title/Abstract] O R "Alzheimer"s"[ Title/ Abstract] OR "dementia"[Title/Abstract]). The search delivered 1267 results and reference lists of selected papers were also searched for potentially relevant studies (Fig. 1).

Titles and abstracts, and then full text articles were reviewed to identify and exclude studies that did not satisfy the previously established criteria: (a) empirical papers, (b) $n>1$ (c) specified diagnosis of DS, and (d) specific reference

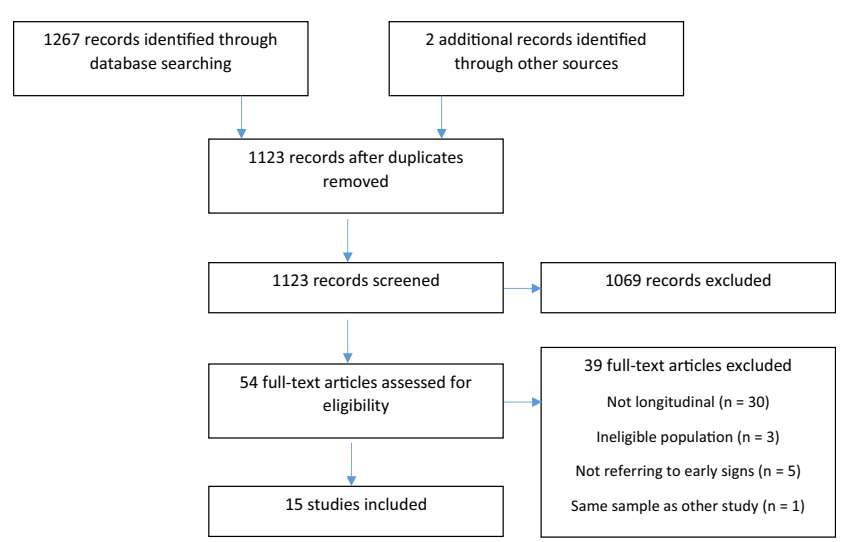

Fig. 1 Flow chart showing the process of selecting studies to be included in systematic review

to the clinical presentation of early stages of DSAD. Longitudinal studies were chosen as this type of study overcomes the issue of cohort effects and allows a better understanding of the dynamic process of cognitive and behavioural change. To minimize bias, the first author discussed the eligibility and validity of included studies with another member of the research team $(\mathrm{AJH})$, solving any disagreement by consensus.

Moreover, as authors of the included studies have used a large variety of terms to refer to the same concept (i.e. "personality changes", "behavioural change", "behavioural excesses and deficits", "maladaptive behaviour"), we will be using the umbrella term Behavioural and Psychological Symptoms of Dementia (BPSD) in order to enhance the overall consistency of the paper.

\section{Results}

In total, 15 papers reporting on 15 longitudinal studies were selected for data extraction and analysis. Data was collected following guidelines set by the Cochrane Collaboration, with the following variables being extracted: study length, participant number and age at each assessment (mean and standard deviation, if recorded), dementia diagnosis, assessment measures and reported progression of symptoms. In cases where the longitudinal aspect was part of a larger cross-sectional study, data were included only from participants for which at least 2 data points were available. Summary statistics (mean ages and percentages) were calculated where they were not explicitly stated by authors. The duration between baseline and follow up varied from 1 year to 47 years and included a total of 831 participants.

A brief analysis of bias was conducted on the included studies by examining the degree to which the sampling frame is representative of the general population and whether the assessment tools have been validated, as well as the response proportion at both baseline and follow up, with minimal risks 
of bias being identified by the authors. Table 1 uses Crombie's Items (Zeng et al. 2015) and the reporting format suggested by the Cochrane Collaboration in order to identify possible areas of bias.

It is also worth mentioning that some of the included studies have overlapping authors (e.g. Kitler et al. 2006; Krinsky-McHale et al. 2002; Devenny et al. 2000; Urv et al. 2008; and Ball et al. 2006; Holland et al. 2000) and since these are longitudinal studies conducted during the same time period, it is likely that some participants overlap within each group, which might impact the overall review.

For each study the following specific aspects were considered: first, evidence for change between time points in scores on cognitive functioning and, secondly, the reported BPSD identified as part of the diagnostic assessment. Where possible, the relationship between these observed changes over time was evaluated. Considering that the length of followup, diagnosis reports and assessment methods varied considerably ( 8 methods of diagnosing dementia, 10 memory tests, 21 instruments for assessing executive dysfunction and 10 measures of behaviour change (Table 2), the results are described through a qualitative synthesis rather than a metaanalysis.

\section{Presentation and Progression of Dementia in the People with DS}

In the general population, mild cognitive impairment (MCI) is regarded as the prodromal stage of dementia, but it has been

Table 1 Risk of bias

\begin{tabular}{|c|c|c|c|c|c|c|c|c|}
\hline & $\begin{array}{l}\text { Appropriateness } \\
\text { of design to } \\
\text { meet the aims }\end{array}$ & $\begin{array}{l}\text { Adequate } \\
\text { description } \\
\text { of the data }\end{array}$ & $\begin{array}{l}\text { Report } \\
\text { the } \\
\text { response } \\
\text { rates }\end{array}$ & $\begin{array}{l}\text { Adequate } \\
\text { representativeness } \\
\text { of the sample to } \\
\text { total }\end{array}$ & $\begin{array}{l}\text { Clearly stated } \\
\text { aims and } \\
\text { likelihood of } \\
\text { reliable and valid } \\
\text { measurements }\end{array}$ & $\begin{array}{l}\text { Assessment } \\
\text { of statistical } \\
\text { significance }\end{array}$ & $\begin{array}{l}\text { Adequate } \\
\text { description } \\
\text { of } \\
\text { statistical } \\
\text { methods }\end{array}$ & Comment \\
\hline Ball et al. 2006 & + & + & + & + & + & + & + & \\
\hline $\begin{array}{l}\text { Adams \& Oliver } \\
2010\end{array}$ & + & $?$ & + & + & + & + & + & $\begin{array}{l}\text { Insufficient } \\
\text { information on } \\
\text { diagnosis rates } \\
\text { at } \mathrm{T} 1\end{array}$ \\
\hline Kitler et al. 2006 & + & + & + & + & + & + & + & \\
\hline $\begin{array}{l}\text { Temple et al. } \\
2001\end{array}$ & + & $?$ & + & + & + & + & + & $\begin{array}{l}\text { Insufficient } \\
\text { information on } \\
\text { diagnostic rates at } \\
\text { T1 }\end{array}$ \\
\hline $\begin{array}{l}\text { Carr and Collins } \\
2014\end{array}$ & $?$ & + & + & - & + & + & + & $\begin{array}{l}\text { Insufficient details on } \\
\text { diagnostic } \\
\text { procedure. All } \\
\text { female sample }\end{array}$ \\
\hline $\begin{array}{l}\text { Cosgrave et al. } \\
2000\end{array}$ & + & + & + & + & + & + & + & \\
\hline $\begin{array}{l}\text { Krinsky-McHale } \\
\text { et al. } 2002\end{array}$ & + & + & + & + & + & + & + & \\
\hline $\begin{array}{l}\text { Nelson et al. } \\
2007\end{array}$ & + & + & + & + & + & + & + & \\
\hline $\begin{array}{l}\text { Margallo-Lana } \\
\text { et al. } 2007\end{array}$ & - & + & + & + & + & + & + & $\begin{array}{l}\text { Different screening } \\
\text { procedures used } \\
\text { based on } \\
\text { availability of } \\
\text { information \& level } \\
\text { of ID }\end{array}$ \\
\hline $\begin{array}{l}\text { McCarron } \\
\text { et al.2014 }\end{array}$ & + & $?$ & + & - & + & + & & $\begin{array}{l}\text { Insufficient } \\
\text { information on } \\
\text { diagnostic rates at } \\
\text { T1. All female } \\
\text { sample }\end{array}$ \\
\hline $\begin{array}{l}\text { Makary et al. } \\
2014\end{array}$ & + & + & + & + & + & + & + & \\
\hline $\begin{array}{l}\text { Holland et al. } \\
\qquad 2000\end{array}$ & + & + & + & + & + & + & + & \\
\hline $\begin{array}{l}\text { Devenny et al. } \\
2000\end{array}$ & + & + & + & + & + & + & + & \\
\hline Urv et al. 2008 & + & + & + & + & + & + & + & \\
\hline $\begin{array}{l}\text { Määttä et al. } \\
2014\end{array}$ & + & + & + & + & + & + & + & \\
\hline
\end{tabular}


Table 2 Variety of assessments included in the systematic review

\begin{tabular}{|c|c|c|}
\hline Abbreviation & Assessment & $\begin{array}{l}\text { Developed by/ } \\
\text { Reported in }\end{array}$ \\
\hline AADS & Assessment for adults with developmental disabilities & Kalsy et al. 2002 \\
\hline ABD-Q & Adaptive Behaviour Dementia Questionnaire & Prasher et al. 2004 \\
\hline BEERY VMI & Beery Visual Motor Integration test & $\begin{array}{l}\text { Beery and Buktenica } \\
1997\end{array}$ \\
\hline BPVS & British Picture Vocabulary Scale 2nd edition & Dunn et al. 2009 \\
\hline CAMCOG & Cognitive section of CAMDEX-DS & Ball et al. 2004 \\
\hline CAMDEX-DS & $\begin{array}{l}\text { The Cambridge Examination for Mental Disorders of Older People with Down's syndrome and Others with } \\
\text { Intellectual Disabilities }\end{array}$ & Ball et al. 2004 \\
\hline CRT & Cued Recall Test & Buschke 2008 \\
\hline DBC-A & Developmental Behaviour Checklist-Adult & Mohr 2004 \\
\hline DMR & Dementia for Mentally Retarded Individuals & Evenhuis 1990 \\
\hline DLSQ & Daily Living Skills Questionnaire & $\begin{array}{l}\text { National Institute of } \\
\quad \text { Ageing } 1989\end{array}$ \\
\hline DSDS & Dementia Scale for Down Syndrome & Gedye 1995 \\
\hline DSMSE & Down's syndrome Mental Status Examination & Haxby 1989 \\
\hline \multirow[t]{4}{*}{ EF battery } & Tower of London & Krikorian et al. 1994 \\
\hline & Weigl card sorting & $\begin{array}{l}\text { Goldstein and Scheerer } \\
1941\end{array}$ \\
\hline & Cats and dogs Stroop task & Gerstadt et al. 1994 \\
\hline & Scrambled boxes & Strauss and Lewin 1982 \\
\hline HBS & Handicaps, behaviour and skills schedule & Wing 1980 \\
\hline IBRMSE & Institute for Basic Research Mental Status Exam & $\begin{array}{l}\text { Wisniewski and Hill } \\
1985\end{array}$ \\
\hline LIPS & Leiter International Performance Scale & Leiter 1940 \\
\hline VABS & Vineland Adaptive Behaviour Scale & Sparrow et al. 1984 \\
\hline WRL & Word List Recall & Kittler et al. 2004 \\
\hline SRT & Serial Reaction Time & Buschke 1973 \\
\hline WPPSI-voc & Vocabulary scale of Wechsler Pre-School and Primary Scale of Intelligence & Wechsler 1967 \\
\hline NBAP-D & Neuropsychology Behaviour and Affect Profile & Nelson et al. 2007 \\
\hline \multirow{9}{*}{$\begin{array}{l}\text { Neuropsychological } \\
\text { battery }\end{array}$} & Boston Naming Test & Kaplan 2001 \\
\hline & Wide Range Achievement Test & $\begin{array}{l}\text { Jastak and Wilkinson } \\
1984\end{array}$ \\
\hline & Verbal fluency & - \\
\hline & BPVS & Dunn et al. 2009 \\
\hline & Fuld Object-Memory test & Fuld 1981 \\
\hline & Visual Motor Integration Test & $\begin{array}{l}\text { Beery and Buktenica } \\
1997\end{array}$ \\
\hline & WISC-III & Wechsler 1974 \\
\hline & WPPSI & Wechsler 1974 \\
\hline & 20-hole foam pegboard VABS & - Sparrow et al. 1984 \\
\hline PPVT-4 & Peabody Picture Vocabulary Test 4th Edition & Dunn 2007 \\
\hline RBMT-C & Rivermead Behavioural Memory Test for Children & $\begin{array}{l}\text { Wilson and } \\
\text { Ivani-Chalian } 1995\end{array}$ \\
\hline RSMB & Reiss Screen for Maladaptive Behaviour & Reiss 1994 \\
\hline S-R paradigm & Simple visual discrimination, reversal learning, Delayed non-match to sample, landmark & Nelson et al. 2007 \\
\hline TSI & Test for Severe Impairment & Albert and Cohen 1992 \\
\hline WISC-R & Wechsler Intelligence Scale for Children-Revised & Wechsler 1974 \\
\hline
\end{tabular}

argued that, in the case of people with DS, the exact hierarchy of loss of function is very difficult to establish (Cosgrave et al. 2000). Out of the 15 studies identified here, which attempted to address this question, nine suggested that 'frontal-like symptoms' were the earliest sign of $\mathrm{AD}$ in this population. Only two studies reported memory as the earliest sign of dementia. Out of the remaining four studies, two reported no decline that could not be accounted for by normal ageing and two did not report the order in which domains of cognitive functioning were affected.
The studies reporting the progression of clinical signs of DSAD are summarized in Table 3 and further discussed in the following sections. It is important to note that the majority of studies included in this review (with the exception of Määttä et al. 2014) have used various screening tools, rather than a diagnosis made by a clinician. Thus, it is possible that discrepancies between results are due to inadequate classification of participants with or without dementia, as well as due to the use of different diagnostic methods in each individual study (Ballard et al. 2016). 


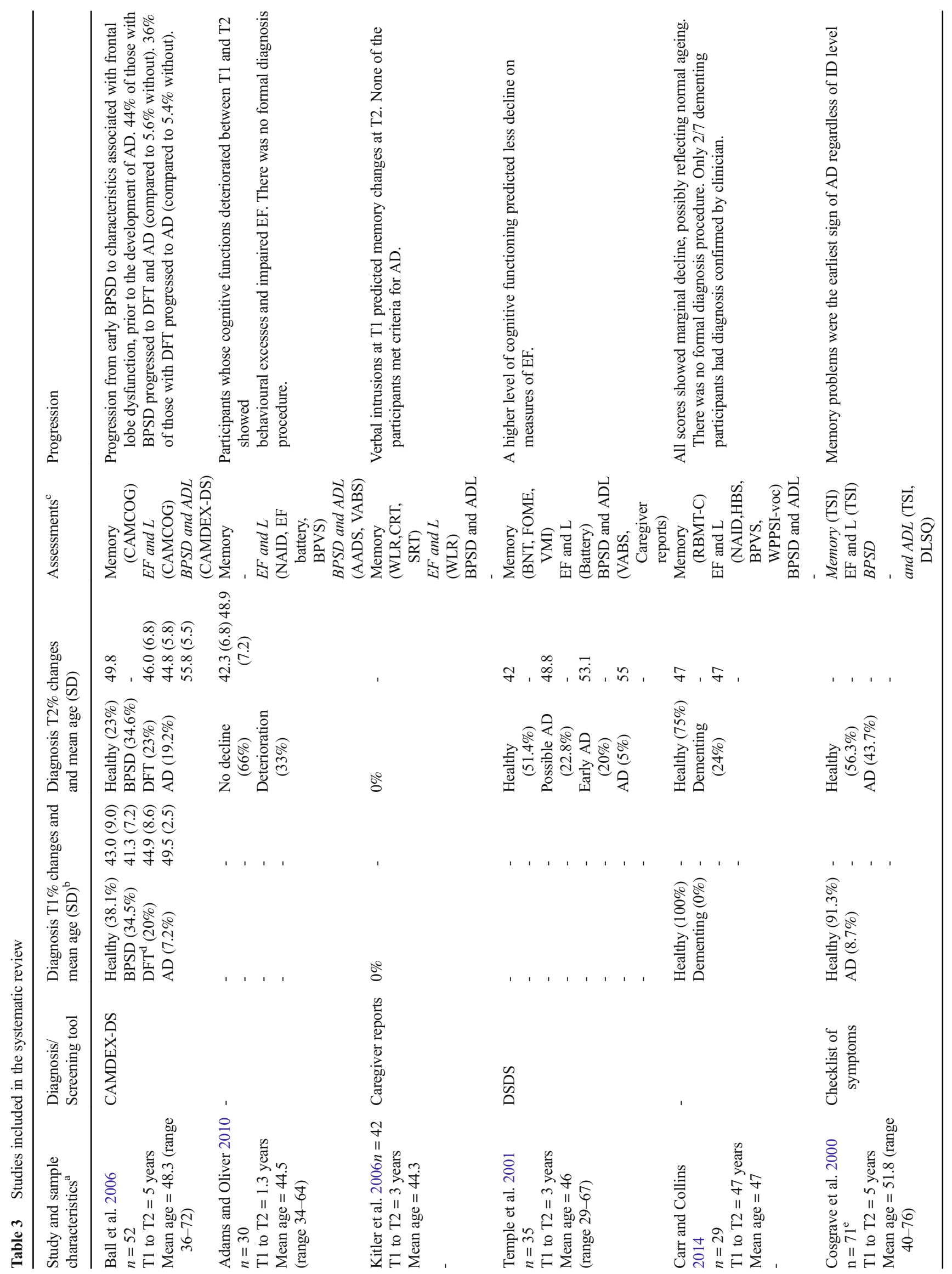




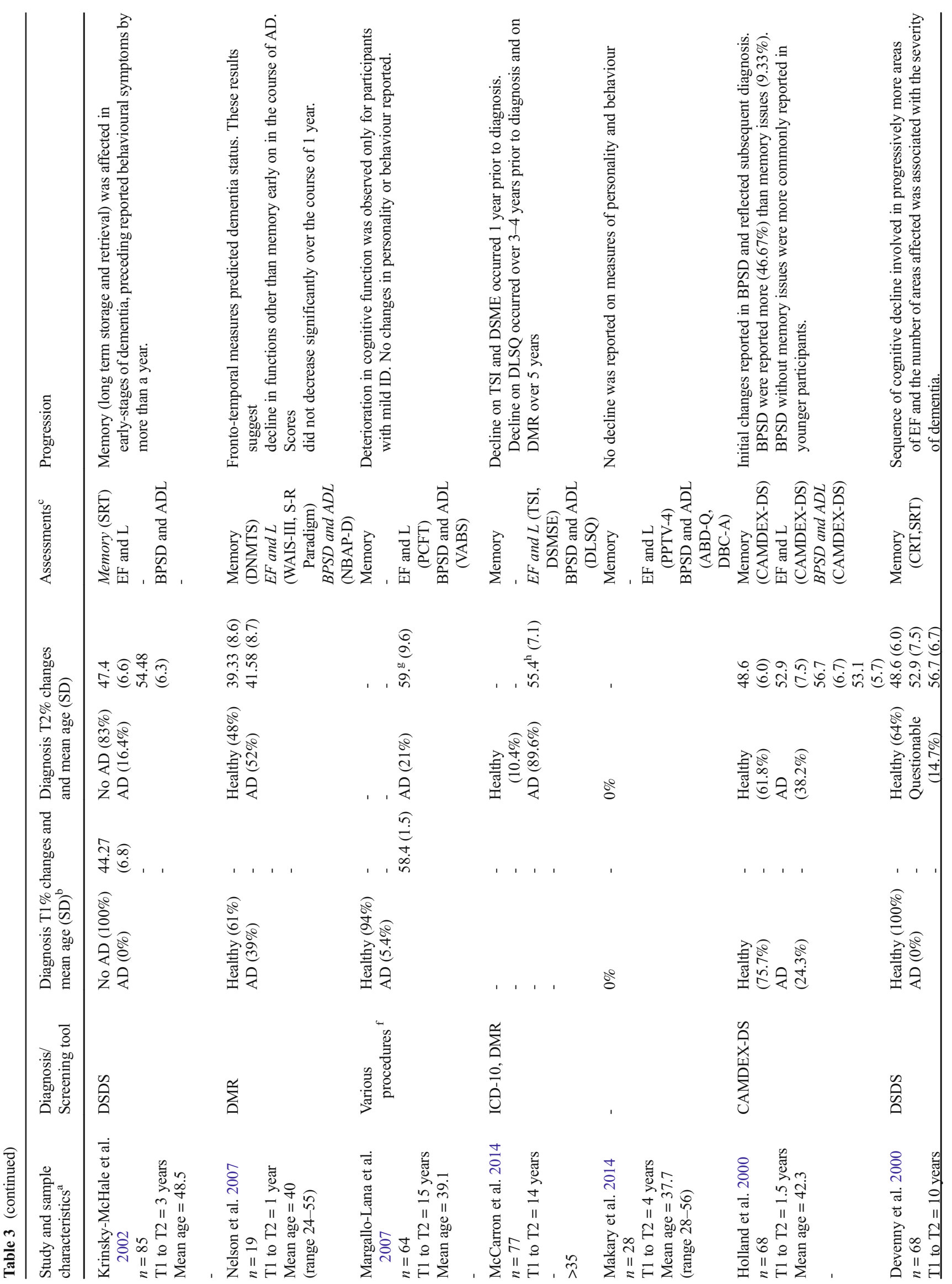




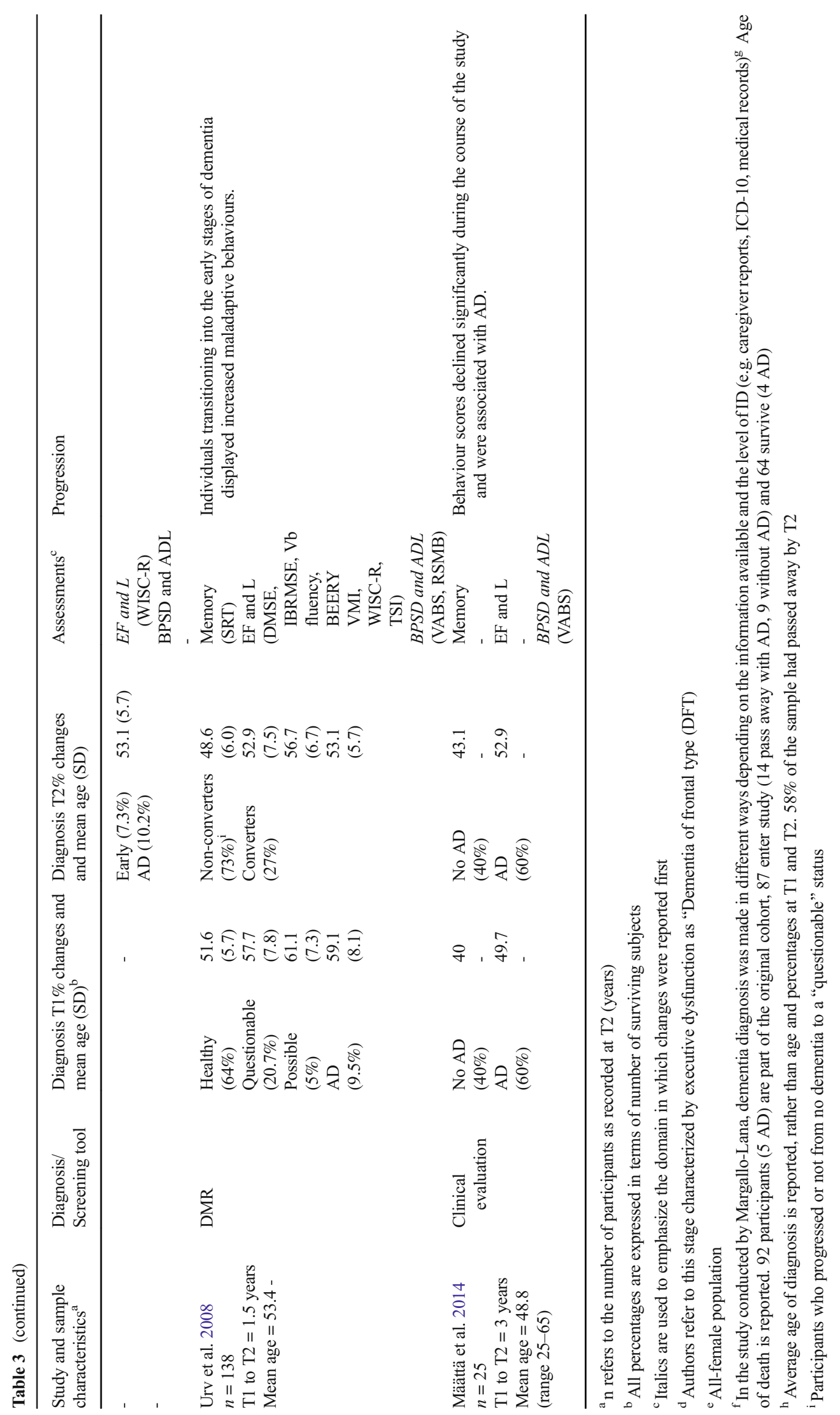




\section{Memory}

DS is known be associated with impairments in working memory, specifically remembering information for short periods of time (Silverman 2007). It has been suggested that tasks that rely on the hippocampus (e.g. associations of items in space and time) are commonly impaired in this population, hence making difficult the measurement of decline in these domains as a marker of AD-related change. By taking into account the level of baseline functioning, researchers interested in memory decline in people with DS have mostly focused on verbal list learning and scene learning (Sabbagh and Edgin 2016).

Compared to the general population where episodic memory impairments characterize prodromal stages of $\mathrm{AD}$ in the majority of cases, only two of the longitudinal studies included in this review identified impairments in memory as one of the earliest symptoms of DSAD (Krinsky-McHale et al. 2002; Cosgrave et al. 2000). Krinsky-McHale et al. (2002) found that decline in memory function scores preceded the onset of global changes associated by the authors with the onset of dementia, as reported in informant interviews. Decline in memory function preceded more global changes by more than a full year and in some cases by up to 3 years. More specifically, verbal explicit memory was one of the first domains that were affected, with individuals' scores on the Selective Reminding Test declining by $20 \%$ on two consecutive test sessions, The authors compared the results of participants with dementia to those of age- and IQ-matched non-demented individuals with DS and concluded that the dramatic declines observed in DSAD were distinguishable from normal ageing pattern. Interestingly, even in cases where participants were capable of performing the task, those in the early stages of dementia showed deficits in their capacity to encode and retrieve information from long-term memory.

This view was supported by a previous study in which memory loss was one of the first identifiable hallmarks of $\mathrm{AD}$ in an all-female sample of older adults with DS (Cosgrave et al. 2000). In this study, participants had difficulty remembering items that they had seen as part of a previous task (i.e. delayed memory) and difficulty remembering in which hand a paper clip was held by the examiner after both hands were placed behind the examiner's back (i.e. immediate memory).

However, these findings were only applicable in the case of individuals with mild (IQ 55-70) and moderate ID (IQ 4055 ), and memory problems were more difficult to identify in participants with more severe intellectual disabilities (severe = IQ $25-40$, or profound = IQ $<25$ ) due to floor effects on established tests. More specifically, participants with IQ under 40 had very low scores on memory tests regardless of dementia diagnosis and thus, these measures may not be suitable as an indicator of decline over time in this population. More recently, in the DSM-V, IQ test scores have been removed from the diagnostic criteria of ID (American Psychiatric Association 2013), emphasizing the need for a more comprehensive assessment in which severity of ID will be based on the level of adaptive functioning, rather than IQ, as the former determines the level of support required (Oakley et al. 2003).

In the study conducted by Devenny et al. (2000), authors suggested that decline does not occur globally but rather as a systematic and progressive loss of cognitive functions, with memory loss being a predominant symptom in all participants who also showed decline on the Block Design and Coding subtests of the WISC-R. These participants were classified as having "questionable decline". However, the authors emphasize the fact that none of these participants had received an official diagnosis from a physician and thus advise caution when interpreting their results, as it is possible that the observed declines were related to some other undetected condition.

A different view, however, is that decline in memory scores (even in the presence of developmental memory impairment) are observed in all ageing individuals with DS, regardless of dementia status (Ball et al. 2006; Devenny et al. 2000; Carr and Collins 2014). It is possible that by examining alternative measures of decline in other cognitive domains, the generalized pattern of deterioration that accompanies old age can be distinguished from preclinical AD. In the study conducted by Ball et al. (2006), informant reported memory changes were not correlated with subsequent diagnosis of $\mathrm{AD}$ and all participants who showed changes in memory also showed BPSD. However, in people with DS, early changes in memory may be more difficult to notice compared to BPSD, the latter having a greater impact on the individual's daily life (Adams and Oliver 2010). Certain learning and memory tasks such as cued-learning and recall tasks may prove to be of a greater sensitivity and specificity for distinguishing between $\mathrm{AD}$ and non-AD in this population (Benejam et al. 2015).

More recently, a review by Sabbagh and Edgin (2016), suggested that the earliest symptoms of dementia in individuals with DS are often subtle but are firstly evident in BPSD rather than episodic memory. They are thus arguing that the late diagnosis of DSAD is often due to the fact that current classification systems have their emphasis on memory impairments, having been modelled after the diagnostic criteria of dementia in the general population and are unfit for use in the DS population (Nieuwenhuis-Mark 2009).

\section{Executive Function and Language}

Functional impairments in executive functioning (executive dysfunction), as referring to informant reported difficulties with various goal-directed behaviours, such as planning and attention, and also performance on specific cognitive tests, have been identified in the majority of selected studies as preceding memory problems in adults with DS. However, in 
the studies reviewed there was not obvious overlap in terms of specific areas of decline identifed by repective authors. In Ball et al. (2006), the most commonly reported changes were impairments in planning, attention and lack of foresight, while in another study (Adams and Oliver 2010), the most affected areas were working memory, agnosia, aphasia and apraxia, with cognitive deterioration not being solely attributable to memory issues. In the Ball et al. (2006) paper, a version of the CAMCOG neuropsychological test battery modified for use with people with DS was completed at baseline and follow up assessments, to provide a measure of decline in global cognitive function. To provide more specific information on the sequence of decline in "frontal lobe associated EF" over the 5 years prior to diagnosis, an additional measure labelled "EF and attention" was designed by combining CAMCOG scores for abstract thinking, attention-calculation, verbal fluency and the clock drawing item. However, impairments in planning and foresight were measured through informant reported changes, rather than a more objective measure. Given the variety of living situations of participants in this study [i.e. residential homes $(82 \%)$, sheltered accommodation (4\%), nursing homes (2\%), with a parent orrelative (13\%)], we advise caution when interpreting these results. The caution is based on research showing that informant reports differ both qualitatively and quantitatively when recorded from personnel in an institution compared to parents (Nieuwenhuis-Mark 2009). Moreover, it is possible that "lack of foresight" could be affected by intellectual ability and this should also be taken into consideration, as 41 out of 55 participants in this study had moderate or severe learning disability.

In one of the studies, executive dysfunction was investigated by looking at verbal intrusions as an indicator of disruption of inhibition control (Kitler et al. 2006). Responding with an irrelevant word during a task of verbal memory retrieval was found to be predictive of performance on two out of three memory tasks administered within the next three years. Therefore, the authors argued that verbal intrusions are an early sign of Alzheimer-related neuropathology, preceding declines in memory. Interestingly, middle aged participants with DS made more verbal intrusions at baseline compared to participants with unspecified ID ( $74 \%$ vs $44 \%$ ), giving further support to the idea that executive functioning is more sensitive to decline in DS than in other populations.

Another component of EF was examined by Nelson et al. (2007), who identified the NBAP Pragnosia scale as useful in classifying $80 \%$ of all dementia cases. The authors argued that impaired pragmatic language function represents an aspect of cognitive decline, as this measure appears to be strongly correlated with the assessment of dementia status (DMR Cognitive Scale). These impairments appeared to be most common in younger subjects, suggesting decline in functions other than memory, early in the course of dementia. More recently however, researchers have argued that verbal scores do not show significant decrease over the course of 47 years (Carr and Collins 2014), but these results might represent a sample bias, as the stronger representation of verbally able women might have influenced the overall stability of verbal scores in the group.

However, the exact sequence in which subdomains of executive functioning are affected has not yet been established. This could be largely due to the heterogeneity of DS phenotypes. Devenny et al. (2000) attempted to answer this question by following up participants over a 10 year period and noting that scores which showed decline early in the disease process were those that required perception of abstract stimuli and visuo-motor coordination. As participants progressed from prodromal stages to early dementia, deficits in comprehension, measures of visuospatial organization and the working memory component of language were observed, followed by vocabulary, information and digit span tasks in the middle stages of AD. As decline associated with the development of $\mathrm{AD}$ seems to involve progressively more areas of cognition and the number of areas in which decline was observed of was correlated to the severity of dementia, the authors conclude that cognitive decline in $\mathrm{AD}$ in people with $\mathrm{DS}$ is not global, but follows a predictable sequence. Executive functioning seems, according to the evidence presented above, to be affected in pre-clinical or early stages of $\mathrm{AD}$ and thus, detecting these changes could prove to be helpful in predicting a later diagnosis of $\mathrm{AD}$.

\section{Behavioural and Psychological Symptoms of Dementia (BPSD)}

Behavioural and Psychological Symptoms of Dementia (BPSD) have been defined as a "heterogeneous range of psychological reactions, psychiatrics symptoms and behaviours resulting from the presence of dementia" (Finkel 2001). Recent literature has suggested that BPSD are reported in the prodromal and early stages of DSAD and might predict a more severe diagnosis. Often, BPSD are reported in the absence of informant observed functional memory decline (Ball et al. 2006), in contrast to the presentation of $\mathrm{AD}$ in the general population, where impairments in episodic memory are commonly the first reported changes.

The hypothesis that BPSD and executive dysfunction precede memory issues in the pre-clinical and early stages of $\mathrm{AD}$ in DS is relatively recent (Ball et al. 2006; Adams and Oliver 2010; Kitler et al. 2006; Nelson et al. 2007; Urv et al. 2008; Määttä et al. 2014; Holland et al. 2000). This systematic review indicates that there is a limited but significant amount of research supporting the hypothesis, indicating that people with DS exhibiting BPSD (i.e. those with a history of the onset of these behaviours as opposed to such behaviours being lifelong) are more likely to decline functionally and on testing have evidence of impaired executive functioning compared to 
those with no such changes ( $44 \%$ compared to $5.6 \%$ of those without BPSD). Later the impaired group are then more likely to exhibit memory problems and meet diagnostic criteria for dementia (Ball et al. 2006). Similarly, in the study conducted by Holland et al. (2000), younger people with DS, who did not yet meet the full criteria for a clinical diagnosis of AD, exhibited more 'frontal-like symptoms', while older people had higher rates of clinically diagnosed AD. These results were supported by Nelson et al. (2007), whose study, although not identifying any significant decline in function, due to the short duration between baseline and follow up, argued for the high reliability and validity of measures of "frontal-like symptoms" in the detection of $\mathrm{AD}$ early in the disease process, suggesting that EF and BPSD may indeed precede or accompany memory changes in this population

This view is also supported by the results of Holland et al. (2000). At the time of an initial assessment more participants were reportedly exhibiting changes in behaviour (46\%) than changes in memory (9\%), whereas at follow up. Older participants had the largest proportion of reported deteriorations in memory and personality, whereas younger participants showed high rates of BPSD in absence of any memory issues, suggesting a trend of decline from behaviour and personality to a combination of domains.

This sequential progression of BPSD between various stages of dementia was further examined in studies that reported correlations between the severity of BPSD and a dementia diagnosis (Määttä et al. 2014; Urv et al. 2008). If indeed BPSD are an indicator of dementia development, the question that arises is whether certain types of behaviours are more likely to develop. In Urv et al. (2008), participants who showed cognitive decline insufficient for a diagnosis of $\mathrm{AD}$ exhibited more BPSD directed towards others (i.e. destructiveness, aggression) than those with a diagnosis of $\mathrm{AD}$, who exhibited more BPSD directed towards the self (i.e. fearfulness, lack of energy, withdrawal, sadness and self-injury). Interestingly, participants who progressed from no diagnosis to questionable dementia were more likely to experience a worsening of scores on certain measures (sadness, increased dependency, confusion, fearful and regressive behaviour and social inadequacy), while the scores of people who were dementia-free at $\mathrm{T} 2$ remained relatively stable on these measures (Urv et al. 2008). Contrary to these findings, Adams and Oliver (2010) and Makary et al. (2014) suggested a more positive pattern of ageing than previously reported.

Similarly to the situation described in the case of executive functioning, a specific pattern of deterioration in BPSD subdomains is difficult to identify. It was proposed that some of the earliest signs of dementia in people with DS are observed in language and socialization difficulties (MargalloLana et al. 2007).

Improving our understanding of BPSD and their relationship to $\mathrm{AD}$ is essential, given that there are people with $\mathrm{DS}$ with very low levels of cognitive functioning who are unable to be diagnosed by measures of cognition alone due to floor levels. This group could, however, be diagnosed on the basis of BPSD and everyday skills (Margallo-Lana et al. (2007). Similar conclusions were reached by Cosgrave et al. (2000), who concluded that even though in their study memory seems to be the earliest symptom, severe intellectual disability conceals the symptoms and thus, BPSD might be easier to detect

Informant reported BPSD such as social withdrawal, apathy (Ball et al. 2006; Holland et al. 2000), inactivity and lack of interest (Adams and Oliver 2010), have been reported in all stages of DSAD (Urv et al. 2008) and it is likely that they significantly affect activities of daily living, with declines having been reported in domestic activity, self-direction and responsibility (Määttä et al. 2014). However, the authors note that depression is one of the factors that correlate most strongly with such changes (Urv et al. 2008) and may often act as a confound due to diagnostic overshadowing (Määttä et al. 2014), alongside hypothyroidism. Because of this potential confound, caution is advised when discussing the role of BPSD in the progression of DSAD and these reported changes must always be analyzed as part of a wider context.

Changes such as restlessness, aggression, repetitive speech and being uncooperative were most often reported in preclinical and early-stages of $\mathrm{AD}$ and thus might represent some of the earliest observable signs of dementia (Adams and Oliver 2010). Observation of these signs seems to be more likely to lead to a referral for dementia assessment and were shown to emerge alongside cognitive decline. In contrast, Carr and Collins (2014) in her long-term follow-up of a birth cohort did not find any increase in aggression with the development of dementia.

Other BPSD, such as emotional lability, lack of concern for other people, stubbornness, disinhibition and impulsivity, were also reported prior to a diagnosis of dementia (Ball et al. 2006). Stubbornness was the second most reported BPSD after apathy in a sample of aging people with DS (Holland et al. 2000), and increases in BPSD were identified as successful predictors of dementia status. When analyzed alongside scores for pragnosia, BPSD successfully predicted over $70 \%$ of dementia cases (Nelson et al. 2007). Urv et al. (2008) suggests that these changes are present before a dementia diagnosis and gradually worsen as dementia progresses, until late stages of $\mathrm{AD}$ when the number of reported distinct behaviours is reduced.

\section{Activities of Daily Living}

Activities of daily living (ADLs) represent a number of activities such as continence, eating, walking or grooming (Ward et al. 1998) and have been shown to be a good predictor of hospital admission and mortality in the elderly population (Ferrucci et al. 1997). Research has suggested that an indicator 
of the development of AD in people with DS is the loss of everyday skills and difficulties with activities of daily living (Margallo-Lana et al. 2007), significantly more affected at age 47, compared to age 30 (Carr and Collins 2014). This pattern of decline seems to be supported by other research (Cosgrave et al. 2000) and it has thus been suggested that investigating ADLs could be very valuable in diagnosing DSAD, especially in people with severe ID, for whom other changes might be difficult to notice (Margallo-Lana et al. 2007). However, caution is advised when interpreting these results, as gender has been suggested to influence rate of decline in ADL in the general population (Ward et al. 1998) with women maintaining skills for a longer time in areas such as food preparation, housekeeping and laundry (Lawton and Brody 1969).

Regarding the hierarchy of loss of ADLs, Cosgrave et al. (2000) noted that loss of independence in personal hygiene was among the first signs of dementia, alongside spatial disorientation. The last skills to be lost were eating and shaking hands, with $86.9 \%$ of participants being able to perform this latter task even in later stages of $\mathrm{AD}$. This is not surprising given the high baseline for the performance of this behavior (i.e. at the beginning of the study, $100 \%$ of participants with moderate ID were able to shake hands with the examiner). However, at the end of the study, many participants were completely dependent on nursing staff, having many other difficulties such as incontinence and severe motor difficulties. Considering the advanced nature of the disease in these participants, it is difficult to pinpoint whether loss of a certain skill is due to loss of social conventions or impaired motor function. Regardless, more recent studies in the general population do suggest that motor skills should be addressed in interventions designed for people with $\mathrm{AD}$ in order to improve their daily living (Oakley et al. 2003).

\section{Discussion}

\section{Early Signs of Dementia in DS}

This review highlights the importance of using a broad spectrum of assessments when examining the sequence of decline of dementia in people with DS, particularly in the early stages during which the presentation of dementia may differ between individuals. While there is no overall consensus, there are a majority of research studies identifying clinical characteristics, other than the development of functional memory changes that occur early in the course of AD. However, an evaluation of the papers included in this systematic review indicates that assessing the hierarchy of decline that accompanies the development of dementia in DS is a challenge. First, from a methodological perspective, change has been identified in two separate ways, one being a structured informant-based interview asking specifically about functional changes and the other being the use of established cognitive tests that can be repeated over time to established whether there has been a change in test scores or not. Secondly, as the diagnosis of AD represents a threshold effect, it is difficult to pinpoint in time the exact onset of symptoms. Thirdly, heterogeneity of symptoms seems to be characteristic of the early stages, and inferences regarding which subdomains of functioning are preferentially affected are very difficult to make. Fourthly, in people with DS it is especially difficult to determine whether the observed symptoms are due to age-related changes in this population or to preexisting cognitive impairments (Ball et al. 2006). In the longest longitudinal study included in this review, scores on the majority of cognitive tests declined by age 47 , regardless of dementia status (Carr and Collins 2014), emphasizing that researchers must be cautious when interpreting results, as for a proportion of participants showing this decline it might suggest pre-clinical symptoms of dementia, it might also reflect normal ageing.

The findings from this systematic review would indicate that BPSD and impairments in executive functioning mark the early course of DSAD. Numerous components of executive function and behavior seem to be affected before memory skills begin to decline, suggesting that current diagnosis procedures of $\mathrm{AD}$ in $\mathrm{DS}$ may not be effective until later stages. This view is supported by a recent review (Ballard et al. 2016), which suggested that dementia in DS initially manifests as BPSD, only to later be followed by changes in cognition.

There are, however, important differences between study findings that may reflect genuine sample differences or may be accounted for by differences in methodology. These differences make an overall picture difficult to ascertain. BPSD and executive dysfunction were often investigated as part of studies primarily concerned with cognition whereas memory changes were reported as part of studies that were carried out with the intention of confirming the presence of memory decline. Moreover, some studies only analyzed a restricted range of abilities and reported on total scores alone, without specifying the exact area of decline. Given the wide variety of screening and diagnosis tools in use, as well as recent research suggesting decline in cognitive function regardless of whether participants have had a formal diagnosis of dementia, we support the recent suggestion made by Ballard et al. (2016), that measures of prevalence reported in published papers should be interpreted with a degree of caution.

Moreover, as with all neuropsychological testing, there is overlap in measurement. For example, a decline in a test of episodic memory would have to be carefully interpreted if there are poor results on attentional tasks. Due to this confounding factor, we advise caution when discussing the results of these papers, as it often is difficult to establish whether a participant's decline on one measure is not influenced by decline in another related domain. 
Lastly, interpreting results was hindered by the fact that the majority of studies did not report on the level of intellectual disability of participants. This issue is essential, considering that the salience, manifestation and degree of impairment determined by the emergence of AD symptoms can vary according to the level of premorbid intellectual capacity and also the person's ability to compensate for the newly acquired deficits. Margallo-Lana et al. (2007) demonstrated that significant cognitive decline at follow - up could only be identified for cases where the baseline score had been at or above the median (mild and moderate ID), with little changes being noticeable for people with severe and profound ID. Moreover, the majority of studies (Adams and Oliver 2010, Kitler et al. 2006, Carr and Collins 2014, Cosgrave et al. 2000, Krinsky-McHale et al. 2002, Nelson et al. 2007, Margallo-Lana et al. 2007, McCarron et al. 2014, Makary et al. 2014, Määttä et al. 2014) did not document whether dementia was at an early or advanced stage. As changes in function seem to vary both quantitatively and qualitatively over the course of $\mathrm{AD}$, future research should report the stage of decline, as well as age and IQ.

\section{Recommendations}

Given the findings of this review, we believe that establishing a baseline level of cognitive functioning and behaviour in people with DS would be extremely useful in following up on changes in domains known to be affected by AD. We therefore advocate the development of a set of common measures appropriate for individuals with DS that would include in depth evaluation of memory, executive function, language and behaviour and that can be used both in clinical settings as well as research. This would allow the implementation of Burt and Aylward's model of best practice (Burt and Aylward 2000) which suggests establishing a baseline of premorbid functioning before the age of 35 , having annual reassessments and conducting a detailed diagnosis in cases where decline is evident. More research needs to be conducted in order to decide on the exact measures to be included in this tool set, given the intra-individual variability in task performance in people with DS (Krinsky-McHale et al. 2008). At present, standard tools developed for the assessment of cognition in the general population often show floor effects when administered to individuals with DS (Stanton and Coetzee 2004) and the majority of the assessment tools are based on the premise that respondents have an IQ in or close to the normative range and require other skills such as good verbal skills, adequate attention or dexterity (Prasher et al. 2004). Burt et al. (2005) have emphasised the need for an appropriate scoring method for diagnosing dementia in this population and suggested that slope scores are more useful than difference scores. For example, institutionalised individuals with DS are known to score lower on neuropsychological tests than people living in the community (Nieuwenhuis-Mark 2009) and thus having an established baseline and measuring change over time in a longitudinal follow up design would be a better approach than cross-sectional studies.

Given that the majority of the studies included in this review point towards BPDS as an early sign of dementia in DS, we believe that there is an urgent need for the development of an acceptable, validated and standardised evaluation scale for BPSD in DS (Sinai et al. 2016), similar to BEHAVE-AD in the general population (Dekker et al. 2015).

Furthermore, diagnostic and assessment measures developed for use in the general population are often used in studies investigating $\mathrm{AD}$ in $\mathrm{DS}$, which often introduces confounding factors (Ballard et al. 2016). This issue was pointed out by Dekker et al. (2015) who stated that although more than 20 scales have been developed to assess BPSD in AD in the general population (Finkel 2001), none of these have been validated in people with DS and therefore are not equally valuable for use in this population as they do not take into consideration factors such as pre-existing behavioural issues associated with ID. In line with the findings of Dekker et al. (2015), such a scale could be implemented in routine practice alongside existing assessment procedures which monitor change over time, as well as being used in longitudinal research and clinical trials.

Having comprehensive assessment tools for outcomes in clinical trials would enable a targeted approach to drug development, which would be essential given recent findings suggesting that people with DS respond differently to treatment when compared to late-onset AD typically developing controls (Ballard et al. 2016). Moreover, a better understanding of BPSD in DS would increase acceptance from the perspective of a carer who would understand that behaviour they perceive as "challenging" is not deliberate but may be a symptom of dementia (Dekker et al. 2015). Imporved recognition of symptoms would facilitate access to non-pharmacological treatments such as behavioural and music therapy and psychosocial interventions (Gauthier et al. 2010).

To account for the fact that BPSD and executive dysfunction seem to be affected earlier than episodic memory in the course of dementia, we suggest Mortimer's reserve capacity hypothesis (1981) as a viable theoretical explanation. According to this model, the frontal lobes of people with DS are underdeveloped and thus a smaller buden of neuropathology in the brain may be required to reach the threshold at which functioning is impaired. Volume reduction of frontal lobes has been observed during childhood, while hippocampal volume reduction has only been reported later in life (Jacola 2012). These observations would account for the preferential decline in areas of cognition sub-served by these areas. Indirect support for Mortimer's reserve capacity hypothesis 
comes from the longitudinal study conducted by Temple et al. (2001), in which progression of dementia appears to be slowed by having high levels of pre-morbid cognitive functioning. The authors suggest that environmental interventions such as improving the level of education and number of years in employment might represent successful strategies to reduce cognitive decline. The suggestion that early clinical presentation of $\mathrm{AD}$ in $\mathrm{DS}$ matches that of frontal-based symptoms can serve as a theoretical foundation for the findings of neuroimaging studies such as the recent amyloid PET imaging with 18F-FDDNP study that showed increased frontal predominance of amyloid pathology in people with DS who had a diagnosis of $\mathrm{AD}$, compared to typically developing patients with late-onset AD (Nelson et al. 2011).

To conclude, even though there is no overall consensus on what represents the earliest observable sign of dementia in DS, this review highlights the heterogeneity of affected domains. BPSD, developing for the first time in later adult life, predicts the subsequent development of dementia in the majority of the included studies. There is also evidence that emergence of BPSD is underpinned by impairments in executive functioning that may implicate impairments in frontal lobe integrity and in related brain networks (Ball et al. 2008). We recommend that future research should investigate a wider variety of processes, to reflect the heterogeneity of domains that seem to be affected in the prodromal and early stages of dementia in this population. Moreover, considering that in the general population amnestic MCI is widely accepted as the prodromal stage of $\mathrm{AD}$, an alternative should be proposed for people with DS, to reflect this difference in progression. The key to early diagnosis is knowing what observed changes should raise the index of suspicion sufficiently to indicate the need for a full diagnostic assessment and cognitive evaluation. The findings of this review are especially relevant given that current diagnosis procedures (ICD-10 and DSM-V criteria) emphasize declines in memory functions and therefore in this population may fail to facilitate the early detection and diagnosis of dementia when it does occur.

Acknowledgments

This systematic review is part of a larger research study funded by the Baily Thomas Charitable Fund, Addenbrookes Charitable Trust and the Health Foundation. Queens' College Cambridge contributed via a grant which enabled the dissemination of these findings at BNA 2015 Festival of Neuroscience in Edinburgh.

Open Access This article is distributed under the terms of the Creative Commons Attribution 4.0 International License (http:// creativecommons.org/licenses/by/4.0/), which permits unrestricted use, distribution, and reproduction in any medium, provided you give appropriate credit to the original author(s) and the source, provide a link to the Creative Commons license, and indicate if changes were made.

\section{References}

Albert, M., \& Cohen, C. (1992). The Test for Severe Impairment: an instrument for the assessment of patients with severe cognitive dysfunction. Journal of the American geriatrics society, 40(5), 449453.

Adams, D., \& Oliver, C. (2010). The relationship between acquired impairments of executive function and behaviour change in adults with down syndrome. Journal of Intellectual Disability Research, 54, 393-405.

American Psychiatric Association. (2013). Diagnostic and statistical manual of mental disorders (5th ed.). DC: Washington.

Annus, T., Wilson, L. R., Hong, Y. T., Acosta-Cabronero, J., Fryer, T. D., Cardenas-Blanco, A., ... \& Menon, D. K. (2015). The pattern of amyloid accumulation in the brains of adults with down syndrome. Alzheimer's \& Dementia.

Ball, S. L., Holland, A. J., Huppert, F. A., Treppner, P., Watson, P., \& Hon, J. (2004). The modified CAMDEX informant interview is a valid and reliable tool for use in the diagnosis of dementia in adults with Down's syndrome. Journal of Intellectual Disability Research, 48(6), 611-620.

Ball, S. L., Holland, A. J., Hon, J., Huppert, F. A., Treppner, P., \& Watson, P. C. (2006). Personality and behaviour changes mark the early stages of Alzheimer's disease in adults with down syndrome: findings from a prospective population-based study. Int. J. Geriat. Psychiatry, 21, 661-673.

Ball, S. L., Holland, A. J., Treppner, P., Watson, P. C., \& Huppert, F. A. (2008). Executive dysfunction and its association with personality and behaviour changes in the development of Alzheimer's disease in adults with down syndrome and mild to moderate learning disabilities. British Journal of Clinical Psychology, 47(1), 1-29.

Ballard, C., Mobley, W., Hardy, J., Williams, G., \& Corbett, A. (2016). Dementia in Down's syndrome. The Lancet Neurology, 15(6), 622636.

Beery, K. E., Buktenica, N. A., \& Beery, N. A. (1997). The BeeryBuktenica developmental test of visual-motor integration: VMI, with supplemental developmental tests of visual perception and motor coordination: administration, scoring and teaching manual. Parsippany, NJ: Modern Curriculum Press.

Benejam, B., Fortea, J., Molina-López, R., \& Videla, S. (2015). Patterns of performance on the modified cued recall test in Spanish adults with down syndrome with and without dementia. American Journal of Intellectual and Developmental Disabilities, 120(6), 481-489.

Bittles, A. H., \& Glasson, E. J. (2004). Clinical, social, and ethical implications of changing life expectancy in down syndrome. Developmental Medicine \& Child Neurology, 46(4), 282-286.

Burt, D. B., \& Aylward, E. H. (2000). Test battery for the diagnosis of demntia in individuals with intellectual disability. Journal of Intellectual Disability Research, 44(2), 175-180.

Burt, D. B., Primeaux-Hart, S., Loveland, K. A., Cleveland, L. A., Lewis, K. R., Lesser, J., \& Pearson, P. L. (2005). Comparing dementia diagnostic methods used with people with intellectual disabilities. Journal of Policy and Practice in Intellectual Disabilities, 2(2), 94 115.

Buschke, H. (1973). Selective reminding for analysis of memory and learning. Journal of Verbal Learning and Verbal Behavior, 12(5), 543-550.

Buschke, H. (2008). Cued recall in amnesia. Journal of Clinical Neuropsychology, 6(4), 433-440. 
Carr, J., \& Collins, S. (2014). Ageing and dementia in a longitudinal study of a cohort with down syndrome. Journal of Applied Research in Intellectual Disabilities, 27, 555-563.

Cosgrave, M. P., Tyrrell, J., McCarron, M., Gill, M., \& Lawlor, B. A. (2000). A five year follow-up study of dementia in persons with down syndrome: early symptoms and patterns of deterioration. Irish Journal of Psychological Medicine, 17(01), 5-11.

Deb, S., Hare, M., \& Prior, L. (2007). Symptoms of dementia among adults with down syndrome: a qualitative study. Journal of Intellectual Disability Research, 51, 726-739.

Dekker, A. D., Strydom, A., Coppus, A. M., Nizetic, D., Vermeiren, Y., Naudé, P. J., et al. (2015). Behavioural and psychological symptoms of dementia in down syndrome: early indicators of clinical Alzheimer's disease? Cortex, 73, 36-61.

Devenny, D. A., Krinsky-McHale, S. J., Sersen, G., \& Silverman, W. P. (2000). Sequence of cognitive decline in dementia in adults with down syndrome. Journal of Intellectual Disability Research, 44(6), 654-665.

Dunn, D. M., \& Dunn, L. M. (2007). Peabody picture vocabulary test: Manual. Minneapolis, MN: Pearson.

Dunn, L. M., \& Dunn, D. M. (2009). The British picture vocabulary scale. London: GL Assessment Limited.

Evenhuis, H. M., Eurlings, H. A. L., \& Kengen, M. M. F. (1990). Dementia Questionnaire for Mentally Retarded Persons (DMR): For Diagnosis of Dementia in Mentally Retarded People-1990. The Netherlands: Hooge Burch Institute for Mentally Retarded People.

Ferrucci, L., Guralnik, J. M., Pahor, M., Corti, M. C., \& Havlik, R. J. (1997). Hospital diagnoses, Medicare charges, and nursing home admissions in the year when older persons become severely disabled. JAMA, 277(9), 728-734.

Finkel, S. I. (2001). Behavioral and psychological symptoms of dementia: a current focus for clinicians, researchers, and caregivers. The Journal of Clinical Psychiatry, 62(Suppl. 2), 3-6.

Fuld, P. A. (1981). The Fuld object memory test. Chicago: The Stoelting Instrument Company.

Gauthier, S., Cummings, J. L., Ballard, C., Brodaty, H., Grossberg, G., Robert, P., et al. (2010). Management of behavioral problems in Alzheimer's disease. International Psychogeriatrics/IPA, 22(3), $346 \mathrm{e} 372$.

Gedye, A. (1995). Dementia scale for Down syndrome manual. Vancouver: Gedye Research and Consulting.

Gerstadt, C. L., Hong, Y. J., \& Diamond, A. (1994). The relationship between cognition and action: performance of children 312-7 years old on a stroop-like day-night test. Cognition, 53(2), 129-153.

Goldstein, K., \& Scheerer, M. (1941). Abstract Psychological Monographs, 53(2), i.

Hartley, D., Blumenthal, T., Carrillo, M., DiPaolo, G., Esralew, L., Gardiner, K., et al. (2014). Down syndrome and Alzheimer's disease: common pathways, common goals. Alzheimer's \& Dementia, $1-10$.

Haxby, J. V. (1989). Neuropsychological evaluation of adults with Down's syndrome: patterns of selective impairment in non-demented old adults. Journal of Intellectual Disability Research, 33(3), 193-210.

Holland, A. J., Hon, J., Huppert, F. A., \& Stevens, F. (2000). Incidence and course of dementia in people with down syndrome: findings from a population-based study. Journal of Intellectual Disability Research, 44, 138-146.

Jacola, L. M. (2012). The relationship between executive function and maladaptive behavior in adolescents with down syndrome. Unpublished doctoral dissertation. University of Cincinnati, Ohio.

Jastak, S., \& Wilkinson, G. S. (1984). The wide range achievement testrevised. Jastak Associates.

Kalsy, S., McQuillan, S., Oliver, C., Hall, S., \& Oyebode, J. (2002). The adults with Down's Syndrome Project: The Assessment of Adults with Developmental Disabilities (AADS) Questionnaire. Birmingham: University of Birmingham \& South Birmingham Primary Care NHS Trust.

Kaplan, E., Goodglass, H., \& Weintraub, S. (2001). Boston naming test. Austin: Pro-ed.

Kitler, P., Krinsky-McHale, S. J., \& Devenny, D. A. (2006). Verbal intrusions precede memory decline in adults with down syndrome. Journal of Intellectual Disability Research, 50, 1-10.

Kittler, P., Krinsky-McHale, S. J., \& Devenny, D. A. (2004). Semantic and phonological loop effects on verbal working memory in middleage adults with mental retardation. American Journal on Mental Retardation, 109(6), 467-480.

Krikorian, R., Bartok, J., \& Gay, N. (1994). Tower of London procedure: a standard method and developmental data. Journal of clinical and Experimental Neuropsychology, 16(6), 840-850.

Krinsky-McHale, S. J., Devenny, D. A., \& Silverman, W. P. (2002). Changes in explicit memory associated with early dementia in adults with down syndrome. Journal of Intellectual Disability Research, 46(3), 198-208.

Krinsky-McHale, S. J., Devenny, D. A., Kittler, P., \& Silverman, W. (2008). Selective attention deficits associated with mild cognitive impairment and early stage Alzheimer's disease in adults with down syndrome. American Journal on Mental Retardation, 113(5), 369-386.

Lai, F., \& Williams, R. S. (1989). A prospective study of Alzheimer's disease in down syndrome. Archives of Neurology, 46, 849-853.

Lawton, M. P., \& Brody, E. M. (1969). Assessment of older people: selfmaintaining and instrumental activities of daily living. Gerontologist, 9, 179-186.

Leiter, R. G. (1940). The Leiter international performance scale (Vol. 1). Barbara: Santa Barbara State College Press.

Määttä, T., Tervo-Määttä, T., Taanila, A., Kaski, M., \& Iivanainen, M. (2014). Adaptive Behaviour Change and Health in Adults with Down Syndrome: A prospective clinical follow-up study, Pharmacology and Nutritional Intervention in the Treatment of Disease, Dr. Faik Atroshi (Ed.), Finland.

Makary, A. T., Testa, R., Einfeld, S. L., Tonge, B. J., Mohr, C., \& Gray, K. M. (2014). The association between behavioural and emotional problems and age in adults with DS without dementia: examining a wide spectrum of behavioural and emotional problems. Research in Developmental Disabilities, 35(8), 1868-1877.

Margallo-Lana, M. L., Moore, P. B., Kay, D. W. K., Perry, R. H., Reid, B. E., Berney, T. P., \& Tyrer, S. P. (2007). Fifteen-year follow-up of 92 hospitalized adults with down syndrome: incidence of cognitive decline, its relationship to age and neuropathology. Journal of Intellectual Disability Research, 51, 463-477.

McCarron, M., McCallion, P., Reilly, E., \& Mulryan, N. (2014). A prospective 14-year longitudinal follow-up of dementia in persons with down syndrome. Journal of Intellectual Disability Research, 58(1), 61-70.

McKhann, G. M., Knopman, D. S., Chertkow, H., Hyman, B. T., Jack, C. R., Kawas, C. H., et al. (2011). The diagnosis of dementia due to Alzheimer's disease: recommendations from the National Institute on Aging-Alzheimer's association workgroups on diagnostic guidelines for Alzheimer's disease. Alzheimer's \& Dementia, 7(3), 263-269.

Mohr, C., Tonge, B. J. \& Einfeld, S. L. (2004). Manual for the Developmental Behaviour Checklist-Adult Version, Melbourne and Sydney, Australia: Monash University Centre for Developmental Psychiatry and Psychology and School of Psychiatry, University of New South Wales.

Mortimer, J. A., Schuman, L., \& French, L. (1981). Epidemiology of dementing illness. In J. A. Mortimer \& L. M. Schuman (Eds.), The epidemiology of dementia: Monographs in epidemiology and biostatistics (pp. 323-333). New York: Oxford University Press. 
National Institute of Aging. National Institute of Aging, Laboratory of Neurosciences; 1989. The daily living skills questionnaire.

Nelson, L. D., Scheibel, K. E., Ringman, J. M., \& Sayre, J. M. (2007). An experimental approach to detecting dementia in down syndrome: a paradigm for Alzheimer's disease. Brain and Cognition, 64, 92-103.

Nelson, L. D., Siddarth, P., Kepe, V., Scheibel, K. E., Huang, S. C., Barrio, J. R., \& Small, G. W. (2011). Positron emission tomography of brain $\beta$-amyloid and tau levels in adults with down syndrome. Archives of Neurology, 68(6), 768-774.

Nieuwenhuis-Mark, R. E. (2009). Diagnosing Alzheimer's dementia in down syndrome: problems and possible solutions. Research in Developmental Disabilities, 30(5), 827-838.

Oakley, F., Duran, L., Fisher, A., \& Merritt, B. (2003). Differences in activities of daily living motor skills of persons with and without Alzheimer's disease. Australian Occupational Therapy Journal, 50(2), 72-78.

Prasher, V., Farooq, A., \& Holder, R. (2004). The adaptive behaviour dementia questionnaire (ABDQ): screening questionnaire for dementia in Alzheimer's disease in adults with down syndrome. Research in Developmental Disabilities, 25, 385-397.

Reiss, S. (1994). Reiss screen for maladaptive behavior: test manual. Worthington: IDS Publishing.

Sabbagh, M., \& Edgin, J. (2016). Clinical assessment of cognitive decline in adults with down syndrome. Current Alzheimer Research, 13(1), 30-34.

Silverman, W. (2007). Down syndrome: cognitive phenotype. Mental Retardation and Developmental Disabilities Research Reviews, 13(3), 228-236.

Sinai, A., Hassiotis, A., Rantell, K., \& Strydom, A. (2016). Assessing specific cognitive deficits associated with dementia in older adults with down syndrome: use and validity of the Arizona cognitive test battery (ACTB). PloS One, 11(5), e0153917.

Sparrow, S. S., Balla, D. A., Cicchetti, D. V., Harrison, P. L., \& Doll, E. A. (1984). Vineland adaptive behavior scales. Circle Pines: American Guidance Service.

Stanton, L. R., \& Coetzee, R. H. (2004). Down's syndrome and dementia. Advances in Psychiatric Treatment, 10, 50-58.
Strauss, H., \& Lewin, I. (1982). An empirical study of the weigl-goldstein-scheerer color-form test according to a developmental frame of reference. Journal of clinical Psychology, 38(2), 367-375.

Strydom, A., Shooshtari, S., Lee, L., Raykar, V., Torr, J., Tsiouris, J., et al. (2010). Dementia in older adults with intellectual disabilities - epidemiology, presentation, and diagnosis. Journal of Policy and Practice in Intellectual Disabilities, 7(2), 96-110.

Suarez-Almazor, M. E., Belseck, E., Homik, J., Dorgan, M., \& RamosRemus, C. (2000). Identifying clinical trials in the medical literature with electronic databases: MEDLINE alone is not enough. Controlled Clinical Trials, 21(5), 476-487.

Temple, V., Jozsvai, E., Konstantareas, M. M., \& Hewitt, T. A. (2001). Alzheimer dementia in down syndrome: the relevance of cognitive ability. Journal of Intellectual Disability Research, 45, 47-55.

Urv, T. K., Zigman, W. B., \& Silverman, W. (2008). Maladaptive behaviours related to dementia status in adults with down syndrome. Americal Journal on Mental Retardation, 2, 73-86.

Ward, G., Jagger, C., \& Harper, W. (1998). A review of instrumental ADL assessments for use with elderly people. Reviews in Clinical Gerontology, 8(01), 65-71.Zeng, X., Zhang, Y., Kwong, J. S. W.

Wechsler, D. (1967). Manual for the Wechsler preschool and primary scale of intelligence. San Antonio: Psychological Corporation.

Wechsler, D. (1974). Manual for the Wechsler intelligence scale for children, revised. San Antonio, TX: Psychological Corporation.

Wilson, B. A., \& Ivani-Chalian, R. (1995). Performance of adults with Down's syndrome on the children's version of the Rivermead behavioural memory test: a brief report. British journal of clinical psychology, 34(1), 85-88.

Wing, L. (1980). The MRC handicaps, behaviour \& skills (HBS) schedule. Acta Psychiatrica Scandinavica, 62(S285), 241-248.

Wisniewski, H. M., \& Hill, A. L. (1985). Clinical aspects of dementia in mental retardation and developmental disabilities. In M. P. Janicki \& H. M. Wisniewski (Eds.), Aging and developmental disabilities (pp. 195-207). Baltimore: Brookes.

Zeng, C., Zhang, C., Li., S., et al. (2015). The methodological quality assessment tools for preclinical and clinical studies, systematic review and meta-analysis, and clinical practice guideline: a systematic review. Journal of Evidence Based. Medicine, 8, 2-1 